\title{
Prevalence and Associated Factors of Induced Abortion Among Women of Reproductive Age Group in Gondar Town, Northwest Ethiopia
}

\author{
Mohammed Oumer ${ }^{1,2, *}$, Agmas Manaye ${ }^{3}$ \\ ${ }^{1}$ Department of Human Anatomy, School of Medicine, College of Medicine and Health Sciences, University of Gondar, Gondar, Amhara, \\ Ethiopia \\ ${ }^{2}$ Department of Epidemiology and Biostatistics, Institute of Public Health, College of Medicine and Health Sciences, University of Gondar, \\ Gondar, Amhara, Ethiopia \\ ${ }^{3}$ Departments of Nursing, College of Medical Sciences, MTY Abyssinia Medical Science College, Gondar, Amhara, Ethiopia
}

Email address:

mohammedoumer58@gmail.com (M. Oumer), tiruman2010@gmail.com (A. Manaye)

${ }^{*}$ Corresponding author

\section{To cite this article:}

Mohammed Oumer, Agmas Manaye. Prevalence and Associated Factors of Induced Abortion Among Women of Reproductive Age Group in Gondar Town, Northwest Ethiopia. Science Journal of Public Health. Vol. 7, No. 3, 2019, pp. 66-73. doi: 10.11648/j.sjph.20190703.11

Received: March 28, 2019; Accepted: April 28, 2019; Published: May 27, 2019

\begin{abstract}
Background:Abortion is the termination of pregnancy by the expulsion of a fetus or embryo from the uterus before viability. An estimated 56 million induced abortions occurred worldwide each year. Ethiopia has the fifth highest number of maternal deaths in the world: one in twenty-seven women die from complications of pregnancy and childbirth annually. Objective:To assess the prevalence of induced abortion and associated factors among women of reproductive age group in Gondar Town, Northwest Ethiopia. Methods:A descriptive cross sectional study design was conducted in 450 reproductive age women, using a pre-tested and structured questionnaire with face-to-face interview, from January 01 to August 07,2018 . Respondents were randomly selected using systematic random sampling method. Descriptive analysis, binary and multivariable logistic regression analysis were used to analyze the data. Results:In this study, the prevalence rate of induced abortion was 40 per 1000 women, making it higher from the previous national rate of abortion for Ethiopia (28/1000 women aged 15-44). Among respondents those are committing induced abortions, $83.33 \%$ was safe abortion. Factors like women's age at first pregnancy (15-19 years [AOR (Adjusted Odds Ratio) $=4.38,95 \%$ CI $(1.21,15.81)$ ]; single marital status $[\mathrm{AOR}=45.05,95 \% \mathrm{CI}(12.02,168.85)]$; unwanted pregnancy $[\mathrm{AOR}=3.21,95 \% \mathrm{CI}(1.16,8.90)]$ and attending school at the time of interfered abortion $[\mathrm{AOR}=5.28,95 \% \mathrm{CI}(1.80,15.49)]$ were significantly associated with committing induced abortion. Conclusions:The study revealed a medium level of prevalence rateof induced abortionamong women of reproductive age group in Gondar Town. Factors like women's ageat first pregnancy, single marital status, unwanted pregnancy and attending school at the time of interfered induced abortion were independently and significantly associated with committing induced abortion.
\end{abstract}

Keywords: Induced Abortion, Prevalence, Women of Reproductive Age, Ethiopia

\section{Introduction}

Abortion is a termination of pregnancy by the expulsion of a fetus or embryo from the uterus before viability [1]. It can occur spontaneously or it can be induced [1-2]. World Health Organization defines induced abortion as a purposeful termination of pregnancy prior to twenty weeks for developed countries and twenty-eight weeks for developing countries [3]. Induced abortion can be safe or unsafe. Unsafe abortion is a procedure for terminating pregnancy either by a person lacking the necessary skills or in an environment lacking minimal medical standards or both [3-4].

Globally, an estimated 56 million induced abortions occurred each year. In all, safe abortion and unsafe abortion estimated as $55 \%$ and $45 \%$ each year, respectively [5]. Among the direct cause of maternal death in the world, unsafe abortions account eight percent of overall maternal 
deaths; at least 22,800 women die annually from complication of unsafe abortions $[2,5]$. According to recent estimates, the global annual rate of abortion for all women of reproductive age is 35 per 1,000 [5]. Each year, approximately 210 million women became pregnant and around one in ten pregnancies ends in an unsafe abortion Worldwide [4, 6]. Almost all abortion-related deaths occur in developing countries, with the highest number occurring in Africa [5].

In Africa, the overall annual abortion rate is 34 per 1,000 women [5]. An estimated annual number of unsafe abortions in Sub-Saharan Africa for women of reproductive ageare 5.5 million $[4,6]$. As many as 36,000 of these women die from the procedure, while millions more experience short or long term complications [2, 4]. Unsafe abortion is the leading cause of maternal mortality in Africa [2, 7]. Unsafe abortionscontinue as a risk factor to a woman's health even if it is preventable [2, 4].

In East Africa, annual abortion rate for all women of reproductive age is 34 per 1,000 [8].

Ethiopia has the fifth highest number of maternal deaths in the world: oneintwenty-seven women die from complications of pregnancy anddelivery annually [9]. Recently, Ethiopia performed an estimated 620, 300 abortions. This corresponds to an annual rate of twenty-eight abortions per 1,000 reproductive aged women, an increase from twenty-two per1,000 women in 2008 [8]. Previously, an estimate of Ethiopian maternal mortality ratio was676 deaths per 100,000 live births [10]. Of 3.27 million pregnancies in Ethiopia, 620,300 end in either spontaneous or induced abortion every year [11]. From those women committed induced abortions, majority of themwere seeking treatment for complications of abortion. About forty-two percent of women had unintended pregnancy in Ethiopia [12]. Low contraceptive utilization lead to high levels of unintended pregnancy, the root cause of abortion [9]. Abortion rate is highest in urban areas of Ethiopia: ninety-two per 1,000 women in Addis Ababa and seventyeight per 1,000 in smaller regions of Ethiopia like Harari and Dire Dawa [8].

Reasons in order to commit induced abortions are either for therapeutic or elective purpose [2, 6]. Therapeutic abortion is performed to save the life of the pregnant woman; whereas, an elective abortion is performed at the request of the pregnant woman for non-medical reasons [2]. Legalizing abortion is highly debatable issue among policymakers throughout the world since illegal abortions have high mortality and morbidity rates in women of reproductive age group [2, 13]. In developing countries, the risk of death following complications of unsafe abortion procedures is many times higher than that of an abortion procedure performed under safe conditions [2, 14]. Therefore, Ethiopia expanded abortion law in 2005, which had previously allowed the procedure only to save the life of a woman. Committing abortion is legal at this time in Ethiopia under certain criteria: rape, incest, fetal impairment, if the pregnancy endangers her or her child's life, continuing the pregnancy or giving birth endangers her life or if she is unable to bring up the child, owing to her status to a physical or mental infirmity $[9,11]$. Although the new law of abortion has implemented, almost six in ten abortions are unsafe in Ethiopia [9, 11].

As evidenced from previous studies, the reasons of unsafe abortion after unwanted pregnancy are inability to support self, having enough children, being very young, and being in school [6, 15-17]. Inability of getting adequate access of contraception services is one of themain risk factor for unsafe abortion problems in the World [6, 18]. Unsafe abortion is one of the main neglected problems of health care in developing countries. This makes the major medical and public health problem in Ethiopia [6, 11]. Increasing the quality of safe abortion services and informing the communities about risks of unsafe abortions are important aspect for reducing maternal mortality and morbidity and prevention of complications related to unsafe abortion [19]. This study findings give valuable information to policymakers, researchers and concerned bodies and important to formulate and design appropriate strategy for interventions. Therefore, the aim of this study is to assess the prevalence rate of inducedabortionand associated factors among women of reproductive age in Gondar Town, Northwest Ethiopia.

\section{Methods and Materials}

\subsection{Study Design and Settings}

A community based descriptive cross sectional study design was undertaken and the study was conducted in Gondar Town, Central Gondar Zone, Amhara Region, Northwest Ethiopiafrom January 01 to August 07, 2018. According to 2017 national reports conducted by the Central Statistical Agency of Ethiopia, Gondar Town has a total population of 360,600 , of which 184,007 are women and 176,593 are men. The Town has 21 kebeles (local),1ReferralHospital and 8 governmental Health Centers [20].

\subsection{Sample Size and Sampling Technique}

The sample size was calculated using a single population proportion formula; by considering $\mathrm{P}$ - value $50 \%$ (since there is no similar study conducted in the study setting), at $95 \%$ confidence interval (CI), 5\% margin of error and 20\% nonresponse rate (77 women to increase precision). $n=z(1-\alpha / 2)^{2}$ * $\mathrm{P}(1-\mathrm{P}) / \mathrm{d}^{2,}(\mathrm{n}=384$ women $)$. Therefore, the final sample size was 461 women.

This study utilized a lottery method (simple random sampling)to select six from twenty-onekebeles (namely, kebele 4, 7, 16, 17, 18 and 19) and systematic random sampling methods to select the study participants. The sample size for each of the selected kebeleswas allocated proportionally to the size of the women of reproductive age group (15-49 years) of each kebele. Besides, the $\mathrm{K}^{\text {th }}$ interval $(\mathrm{k}=43)$ was calculated by using the estimated number of women of reproductive age group to the sample size (the 
number of reproductive age women for sampling frame was obtained from each kebele's health extension workers). All randomly selected women of reproductive age group who live for the last six months in the selected kebeles and having at least one pregnancy history during data collection periodwereincluded in the study.

\subsection{Study Variables}

Induced abortion is a dependent variable. Independent variables include socio-demographic variables: women's age, religion, ethnicity, marital status, educational status, occupation and monthly income of the family. And, reproductive and maternalrelated variables:women'sage at first pregnancy, number of pregnancies, number of children alive, family size, weatherpregnancy is wanted and attending school at the time of interferedabortion.

\subsection{Data Collection Tools Techniques and Procedures}

Data were collected by directface-to-face interview using structured Amharic version questionnaireaboutprevalence of induced abortion and associated factors among women of reproductive age group. The questioner was first prepared in English and translated into Amharic (local language) and back to English to keep consistency of meaning (Supplementary material 5). Data collection questionnaire was adapted from tools used to assess induced abortion prevalence in different literatures to satisfy the objectives this study. The questionnaire has foursub-topics. Of them: sociodemographic, reproductive and maternal and prevalencerelated characteristics (Supplementary material 4). Trained clinical nurses collected the data.

\subsection{Data Processing and Analysis}

The collected data were checked for completeness, accuracy and clarity. The collected data were entered, cleaned, validated and analyzed by the investigators using SPSS version 20 (Statistical Package for Social Sciences). The information that needs coding was coded and missing values were considered before analysis. As result, findings were presented in the form of text, tables and graphs using frequencies and summary statistics. The outcome variable, induced abortion was coded as $\mathrm{No}=0$ and $\mathrm{Yes}=1$. Descriptive analysis was done to describe the frequency and percentage of dependent and independent variables. Binary logistic regression and multivariable logistic regression analysis were done to describe the association between dependent and independent variables and independent predictors of prevalence of induced abortion. Crude odds ratio and adjusted odds ratio were used for testing of the association between independent and dependent variables. Covariates that have P-value of $<0.05$ at the bivariate analysis were included in the multivariable logistic regression to control all possible confounding factors. Overall, aP-value less than 0.05 were consideredstatistically significant association.

\subsection{Data Quality Control and Management}

The questionnaire was pre-tested in similar setting by principal investigators prior to the data collection on five percent of total sample size (23 women) at one of kebele, which was not the part of the main study. Revisions and adjustments were made after pre-test: some unnecessary questions were excluded and missed questions were incorporated. The collected data were also crosschecked on each day of activity for consistency and completeness. Additionally, data collectors were trained and close supervision was made during the data collection.

\subsection{Ethical Consideration}

This study was reviewed and approved by ethical review board of MTY Abyssinia Medical Science College. Ethical clearance was obtained from the ethical review committee of MTY Abyssinia Medical Science College Research and Publication Office (Supplementary material 3). The purpose of the study was described to all women, and all information obtained from them was secured and kept confidential (Supplementary material 1). To ensure confidentiality, the names were avoided from thequestionnaire. Written or oral (For those unable to read and write) informed consents were obtained from respondents who participated in the study (Supplementary material 2).

\section{Results}

\subsection{Socio-Demographic Characteristics of Study Participants}

Four hundred fifty women of reproductive age groupwere involved in the study (response rate $=97.61 \%$ ), of whom 142 (31.6\%) were $25-29$ years. Of the total respondents, majority of them wereAmhara in ethnicity $(91.3 \%)$, Orthodox in their religion (73.6\%), marriage $(85.8 \%)$ and degree and above holder in their education $(23.6 \%)$. About half of respondents were homemakers in occupation (50.9\%) (Table 1$)$.

Table 1. Socio-demographic characteristics of reproductive age women at Gondar Town, Northwest Ethiopia, 2018.

\begin{tabular}{lll}
\hline Characteristics & $\begin{array}{l}\text { Frequency } \\
(\mathbf{n = 4 5 0 )}\end{array}$ & $\begin{array}{l}\text { Percent } \\
(\%)\end{array}$ \\
\hline Age of the respondent (in years) & & \\
$15-19$ & 23 & 5.1 \\
$20-24$ & 116 & 25.8 \\
$25-29$ & 142 & 31.6 \\
$30-34$ & 71 & 15.8 \\
$35-39$ & 67 & 14.9 \\
40 and above & 31 & 6.9 \\
Ethnicity & & \\
Amhara & 411 & 91.3 \\
Oromo & 12 & 2.7 \\
Tigray & 27 & 6.0 \\
Religion & & \\
Orthodox & 331 & 73.6 \\
Muslim & 86 & 19.1 \\
Catholic & 9 & 2.0 \\
Protestant & 24 & 5.3 \\
\hline
\end{tabular}




\begin{tabular}{lll}
\hline Characteristics & $\begin{array}{l}\text { Frequency } \\
\text { (n=450) }\end{array}$ & $\begin{array}{l}\text { Percent } \\
(\mathbf{\%})\end{array}$ \\
\hline Marital status & & \\
Married & 386 & 85.8 \\
Divorced & 20 & 4.4 \\
Single & 35 & 7.8 \\
Widowed & 9 & 2.0 \\
Educational status of respondent & & \\
Unable to read and write & 66 & 14.7 \\
Able to read and write & 29 & 6.4 \\
Primary Education & 26 & 5.8 \\
Junior & 44 & 9.8 \\
Secondary Education & 67 & 14.9 \\
Preparatory Education & 55 & 12.2 \\
Certificate and Diploma holder & 57 & 12.7 \\
Degree holder and above & 106 & 23.6 \\
Occupation of the respondent & & \\
House wife & 229 & 50.9 \\
Merchant & 46 & 10.2 \\
Government employee & 94 & 20.9 \\
Daily labourer & 19 & 4.2 \\
Farmer & 8 & 1.8 \\
Student & 44 & 9.8 \\
Private employee & 10 & 2.2 \\
Monthly income ( in Ethiopian Birr) & & \\
×600 & 37 & 8.2 \\
601 - 1650 & 104 & 23.1 \\
1651 - 3200 & 85 & 18.9 \\
3201 - 5250 & 90 & 20.0 \\
5251 and above & 82 & 18.2 \\
No income & 52 & 11.6 \\
\hline & &
\end{tabular}

\subsection{Reproductive and Maternal Characteristics}

The majority of the respondent's age at first pregnancy (46.2\%) was from 20-24 years. Among all respondents, $56.0 \%$ had $1-2$ number of pregnancies, $71.8 \%$ had $1-3$ number of live children, $51.3 \%$ had $4-6$ number of family size, $67.6 \%$ were their pregnancy wanted and $70.0 \%$ were not attended school at the time of interfered (Table 2).

Table 2. Reproductive health characteristics of reproductive age women at Gondar Town, Northwest Ethiopia, 2018.

\begin{tabular}{lll}
\hline Reproductive characteristics & Frequency $(\mathbf{n}=\mathbf{4 5 0})$ & Percent $(\%)$ \\
\hline Age at first pregnancy in years & & \\
$10-14$ & 0.00 & 0.00 \\
$15-19$ & 79 & 17.6 \\
$20-24$ & 208 & 46.2 \\
25 and above & 163 & 36.2 \\
Number of pregnancies & & \\
$1-2$ & 252 & 56.0 \\
$3-4$ & 136 & 30.2 \\
$5-6$ & 62 & 13.8 \\
Number of live children & & \\
$1-3$ & 323 & 71.8 \\
$4-6$ & 127 & 28.2 \\
Family size & 143 & \\
$1-3$ & 231 & 31.8 \\
$4-6$ & 76 & 51.3 \\
7 and above & & 16.9 \\
Pregnancy & 304 & \\
Wanted & 146 & 67.6 \\
Unwanted & & 32.4 \\
Attending school at time of interfered & 135 & 30.0 \\
Yes & 315 & 70.0 \\
No & &
\end{tabular}

\subsection{Induced Abortion Prevalence and Related issues}

Of 450 respondents, $5.8 \%$ were ever had any previous abortions. About $96.15 \%$ of respondents had 1-2 numbers of abortions. In all, $4.0 \%$ of respondents had induced type of abortion (40 per 1000 women). Among respondents having induced abortions, $83.33 \%$ was safe abortion. The most visited place for committing induced abortion was health institutions $(83.33 \%)$. Trained health workers $(83.33 \%)$ were the common doer ofcommittinginduced abortions (Table 3 ).

Table 3. Prevalence of induced abortion and related issues among women of reproductive age in Gondar Town, Northwest Ethiopia, 2018.

\begin{tabular}{|c|c|c|c|}
\hline Induced abortion & Response & $\begin{array}{l}\text { Frequency } \\
(n=450)\end{array}$ & $\begin{array}{l}\text { Percent } \\
(\%)\end{array}$ \\
\hline \multirow{6}{*}{$\begin{array}{l}\text { Ever had any } \\
\text { abortions } \\
\text { Number of } \\
\text { abortions }(\mathrm{n}=26) \\
\text { Ever hadpregnancy } \\
\text { induced /Interfered }\end{array}$} & Yes & 26 & 5.8 \\
\hline & No & 424 & 94.2 \\
\hline & $1-2$ & 25 & 96.15 \\
\hline & $3-4$ & 1 & 3.85 \\
\hline & No & 432 & 96.0 \\
\hline & Yes & 18 & 4.0 \\
\hline \multirow{3}{*}{$\begin{array}{l}\text { Place of induced } \\
\text { abortion }(n=18)\end{array}$} & Health institutions & 15 & 83.33 \\
\hline & $\begin{array}{l}\text { Community by tradition } \\
\text { (Inducers house ) }\end{array}$ & 3 & 16.67 \\
\hline & Patients house & 0 & 0 \\
\hline \multirow{3}{*}{$\begin{array}{l}\text { Doer of induced } \\
\text { abortion }(n=18)\end{array}$} & Trained health worker & 15 & 83.33 \\
\hline & Traditional attendant & 3 & 16.67 \\
\hline & Self & 0 & 0 \\
\hline
\end{tabular}

Common reasons for committing induced abortion were unplanned pregnancy (44.44\%) followed by for educational purposes (16.67\%) (Figure 1).

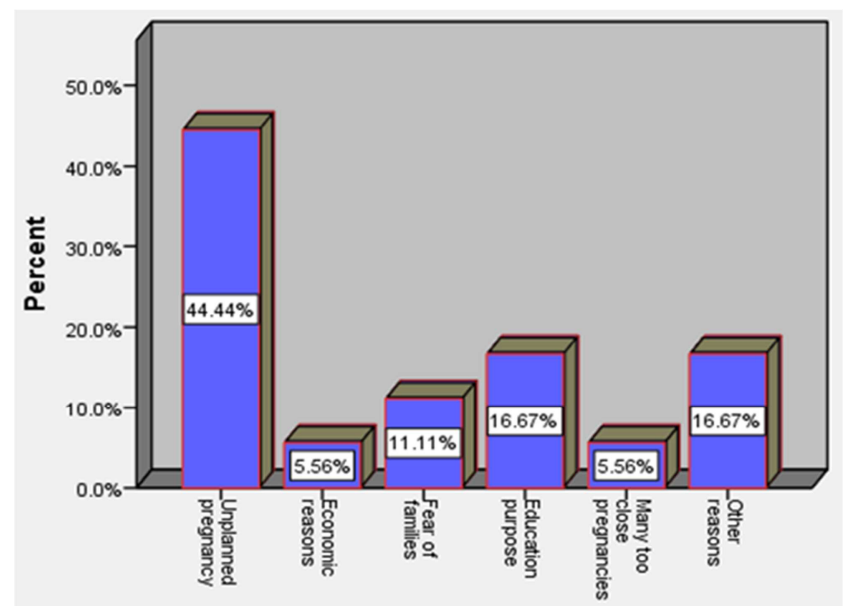

Figure 1. Reasons for resorting induced abortion among women of reproductive age $(n=18)$ at Gondar Town, Northwest Ethiopia, 2018.

\subsection{Factors Associated with Induced Abortion}

\subsubsection{Socio-Demographic Related Factors}

Binary logistic regression showed that respondents age 1519 years and single marital statuswere factors associated with the prevalence of induced abortion.

Variables which show statically significant association $(\mathrm{P} \leq 0.05)$ in binary logistic regression were entered to multivariable logistic regressionto rule out confounders. The odds of having induced abortion were 45 times [AOR = 
45.05 (12.02, 168.85)]greater for women with a single marital status as compared with women of married marital

status (Table 4).

Table 4. Bivariate and multivariable logistic regression analysis on socio-demographic factors associated with induced abortion among women of reproductive age in Gondar Town, Northwest Ethiopia, 2018.

\begin{tabular}{|c|c|c|c|c|c|}
\hline \multirow{2}{*}{ Characteristics } & \multicolumn{2}{|c|}{ Induced abortion } & \multirow{2}{*}{ Crude OR $(95 \%$ CI) } & \multirow{2}{*}{ Adjusted OR (95\% CI) } & \multirow{2}{*}{ P-value**: } \\
\hline & No & Yes & & & \\
\hline Age of the respondent (in years) & & & & & 0.004 \\
\hline $15-19$ & 17 & 6 & $10.59(1.17,95.47)^{*}$ & $11.00(0.83,146.4)$ & 0.07 \\
\hline $20-24$ & 108 & 8 & $2.22(0.27,18.47)$ & $1.91(0.17,21.25)$ & 0.60 \\
\hline $25-29$ & 141 & 1 & $0.21(0.01,3.50)$ & $0.17(0.01,3.38)$ & 0.24 \\
\hline $30-34$ & 70 & 1 & $0.43(0.03,7.08)$ & $0.23(0.01,4.76)$ & 0.34 \\
\hline $35-39$ & 66 & 1 & $0.46(0.03,7.51)$ & $0.61(0.03,13.17)$ & 0.75 \\
\hline 40 and above & 30 & 1 & 1.00 & 1.00 & \\
\hline \multicolumn{6}{|l|}{ Ethnicity } \\
\hline Amhara & 396 & 15 & $0.47(0.10,2.19)$ & - & \\
\hline Oromo & 11 & 1 & $1.14(0.09,13.89)$ & - & \\
\hline Tigray & 25 & 2 & 1.00 & - & \\
\hline \multicolumn{6}{|l|}{ Religion } \\
\hline Orthodox & 320 & 11 & $0.79(0.10,6.40)$ & - & \\
\hline Muslim & 81 & 5 & $1.42(0.16,12.77)$ & - & \\
\hline Catholic & 8 & 1 & $2.88(0.16,51.53)$ & - & \\
\hline Protestant & 23 & 1 & 1.00 & & \\
\hline Marital status & & & & & $<0.001$ \\
\hline Married & 381 & 5 & 1.00 & 1.00 & \\
\hline Divorced & 19 & 1 & $4.01(0.45,36.05)$ & $4.05(0.40,41.44)$ & 0.24 \\
\hline Single & 24 & 11 & $34.93(11.23,108.63)^{*}$ & $45.05(12.02,168.85)^{*}$ & $<0.001$ \\
\hline Widowed & 8 & 1 & $9.53(1.00,91.13)^{*}$ & $5.08(0.46,56.31)$ & 0.18 \\
\hline Educational status of respondent & & & & & 0.13 \\
\hline Unable to read and write & 64 & 2 & $1.07(0.18,6.60)$ & - & \\
\hline Able to read and write & 28 & 1 & $1.23(0.12,12.25)$ & - & \\
\hline Primary Education & 25 & 1 & $1.37(0.14,13.77)$ & - & \\
\hline Junior & 42 & 2 & $1.64(0.26,10.14)$ & - & \\
\hline Secondary Education & 65 & 2 & $1.06(0.17,6.49)$ & - & \\
\hline Preparatory Education & 53 & 2 & $1.30(0.21,7.99)$ & - & \\
\hline Certificate and Diploma holder & 52 & 5 & $3.30(0.76,14.35)$ & - & \\
\hline Degree holder and above & 103 & 3 & 1.00 & & \\
\hline \multicolumn{6}{|l|}{ Occupation of the respondent } \\
\hline House wife & 225 & 4 & 1.00 & & \\
\hline Merchant & 43 & 3 & $3.92(0.85,18.16)$ & - & \\
\hline Government employee & 89 & 5 & $3.16(0.83,12.04)$ & - & \\
\hline Daily labourer & 18 & 1 & $3.13(0.33,29.45)$ & - & \\
\hline Farmer & 7 & 1 & $8.04(0.79,81.51)$ & - & \\
\hline Student & 41 & 3 & $4.12(0.89,19.07)$ & - & \\
\hline Private employee & 9 & 1 & $6.25(0.63,61.74)$ & - & \\
\hline \multicolumn{6}{|c|}{ Monthly income ( In Ethiopian Birr) } \\
\hline$\leq 600$ & 34 & 3 & $2.21(0.35,13.91)$ & - & \\
\hline $601-1650$ & 99 & 5 & $1.26(0.24,6.74)$ & - & \\
\hline $1651-3200$ & 84 & 1 & $0.30(0.03,3.37)$ & - & \\
\hline $3201-5250$ & 87 & 3 & $0.86(0.14,5.34)$ & - & \\
\hline 5251 and above & 78 & 4 & $1.28(0.23,7.26)$ & - & \\
\hline No income & 50 & 2 & 1.00 & & \\
\hline
\end{tabular}

Key: * statistically significant at p-value $<0.05$ in binary and multivariable logistic regression analysis, P-value** for multivariable logistic regressionanalysis; $\mathrm{COR}=$ Crude Odds Ratio, $\mathrm{AOR}=$ Adjusted Odds Ratio.

\subsubsection{Reproductive and Maternal Related Factors}

Binary logistic regression showed that respondent's age at first pregnancy, unwanted pregnancy and attending schoolat the time of interfered were factors associated with prevalence of induced abortion.

Variables that show statically significant association in binary logistic regressionwere entered to multivariable logistic regressionto rule outconfounders. The odds of becoming 15-19 years age at first pregnancy were 4 times
$[\mathrm{AOR}=4.38,95 \% \mathrm{CI}(1.21,15.81)]$ more likely to commit induced abortion as compared to respondents with 25 and above years of age. The odds of having unwanted pregnancy were 3 times $[\mathrm{AOR}=3.21,95 \%$ CI $(1.16,8.90)]$ more likely to commit induced abortion as compared to respondents having wanted pregnancy. Odds of attending school during interfered were 5 times $[\mathrm{AOR}=5.28,95 \% \mathrm{CI}(1.80,15.49)$ ] more likely to commit induced abortion as compared to respondents without attending school (Table 5). 
Table 5. Bivariate and multivariable logistic regression analysis on reproductive health related factors associated with induced abortion among women of reproductive age in Gondar Town, Northwest Ethiopia, 2018.

\begin{tabular}{|c|c|c|c|c|c|}
\hline \multirow{2}{*}{ Reproductive characteristics } & \multicolumn{2}{|c|}{ Induced abortion } & \multirow{2}{*}{ Crude OR (95\% CI) } & \multirow{2}{*}{ Adjusted OR (95\% CI) } & \multirow{2}{*}{ P-value** } \\
\hline & No & Yes & & & \\
\hline Age at first pregnancy (in years) & & & & & 0.02 \\
\hline $15-19$ & 71 & 8 & $4.48(1.31,15.36)^{*}$ & $4.38(1.21,15.81)^{*}$ & 0.02 \\
\hline $20-24$ & 202 & 6 & $1.18(0.33,4.26)$ & $1.08(0.29,4.00)$ & 0.91 \\
\hline 25 and above & 159 & 4 & 1.00 & 1.00 & \\
\hline \multicolumn{6}{|l|}{ Number of pregnancies } \\
\hline $1-2$ & 245 & 7 & 1.00 & & \\
\hline $3-4$ & 129 & 7 & $1.90(0.65,5.53)$ & & \\
\hline $5-6$ & 58 & 4 & $2.41(0.68,8.52)$ & & \\
\hline \multicolumn{6}{|l|}{ Number of children alive } \\
\hline $1-3$ & 313 & 10 & 1.00 & & \\
\hline $4-6$ & 119 & 8 & $2.10(0.81,5.46)$ & & \\
\hline \multicolumn{6}{|l|}{ Family size } \\
\hline $1-3$ & 139 & 4 & 1.00 & - & \\
\hline $4-6$ & 222 & 9 & $1.41(0.43,4.66)$ & - & \\
\hline 7 and above & 71 & 5 & $2.45(0.64,9.40)$ & - & \\
\hline \multicolumn{6}{|l|}{ Pregnancy } \\
\hline Wanted & 297 & 7 & 1.0 & 1.0 & \\
\hline Unwanted & 135 & 11 & $3.46(1.31,9.11)^{*}$ & $3.21(1.16,8.90)^{*}$ & 0.025 \\
\hline \multicolumn{6}{|c|}{ Attending school at time ofinterfered } \\
\hline Yes & 122 & 13 & $6.61(2.31,18.93)^{*}$ & $5.28(1.80,15.49) *$ & 0.002 \\
\hline No & 310 & 5 & 1.00 & 1.00 & \\
\hline
\end{tabular}

Key: *statistically significant at p-value $<0.05$ in binary and multivariable logistic regression analysis, $\mathrm{P}$-value** for multivariable logistic regressionanalysis.

\section{Discussion}

This community-basedstudy conductedtodeterminethe prevalence and identify factors associated with induced abortion in Gondar Town. Accordingly, women's age at first pregnancy, marital status, unwanted pregnancy and attending schoolat the time of interfered were independently and significantly associated with the prevalence of induced abortion.

In this study, the prevalence rate of induced abortion was $4.0 \%$ (40 per 1000 women). This finding is almost in line with findings fromWolaitaSodo University 6.5\% [21] and Dabat and Adet study 4.8\% [20]. However, this study finding is lower than the findings from Nigeria 10\% [22], Eritrea $11 \%$ [23], Guraghe Zone, Ethiopia12.3\% [6]andHarar, Ethiopia 14.4\% [24]. The possible explanations for the observed differences might be a difference in study settings, year of study, sample size and study design. Although it is comparable with some other studies, it is slight high prevalence in the context of our locality. The reason for this increment is it urban area and some of our selected kebelesare near the College and University institutions (students are more liable for induced abortion), that may cause this increment.

In this study:respondent socio-demographic variables, reproductive and maternal variables analyzed for induced abortion prevalence. Women's age at first pregnancy 15-19 years werepositivelyassociatedwithinduced abortion. This finding is in line with the study conductedinHarar [24], Dabat and Adet [20], Jimma Hospital [25], Gammbella Hospital [26], Jimma Town [27], Guraghe Zone [6] and Jimma Ethiopia [28]. Younger women were more likely to commit induced abortions than older ones. The possible explanation is could be women at this age group become economically dependent, unstable marital relationship, and have not completed their education unlike the older age groups [6]. Young women below 24yearswere more likely to have sexual intercourse than young men in the same age group. Pregnancy related health risks are much higher among women under 18 years and these girls almost five times more likely to die during pregnancy and delivery than women aged 20-24 years [20]. The odds of having induced abortion were forty five times greater for women with a single marital status compared with women of married marital status. This finding is in agreement with the study conducted in Gammbella Hospital [26], Dabat and Adet [20], Harar [24] and Jimma Ethiopia [28]. The possible explanation could be due to some single girls become pregnant from their spouse before marriage without knowing their parents so that fear of the family and the community predisposes them for committing induced abortion. The odds of having induced abortion were three times greater for women having unwanted pregnancy compared with women having wanted pregnancy. This finding is in line with the study inGuraghe Zone [6] and Addis Ababa [29]. The possible explanation could be women committing induced abortion usually have unplanned or unwanted pregnancy as well as there is lack of knowledge about contraception and its utilization. On the other hand, women decided to have fewer children, they will use contraceptive methods to limit their children [6]. Pregnancy during attending school positively associated with committing induced abortion. This finding is similar to another study in Jimma, Ethiopia [28]. This may be related with their plan of ending their school before having child and other related factors. Education is one of the main reasons to dislike the pregnancy [6]. 
One of the strength of this study was large sample. This increases the representativeness (precision) of the source population. In addition, this study is community-based study by randomly selecting study participants. These differences make induced abortion prevalence difference among with other previous studies.

\section{Conclusion}

The findings of the present study summarized as:

The study revealed a medium level of prevalence rateof induced abortionamong women of reproductive age group in Gondar Town.

Factors like women's ageat first pregnancy, single marital status, unwanted pregnancy and attending school at the time of interfered induced abortion were independently and significantly associated with committing induced abortion.

Generally, focusing on factors predicting the likelihood of induced abortion (Like unwanted pregnancy) is one of the recommendations for Gondar Town Health Office, policymakers and other concerned bodies to reduce the prevalence rate of induced abortion.

\section{Declarations}

Ethics Approval and Consent to Participate

This study was reviewed and approved by ethical review board of MTY Abyssinia Medical Science College. Ethical clearance was obtained from the ethical review committee of MTY Abyssinia Medical Science College Research and Publication Office (Supplementary material 3 as reference number MTYAMSC/11337/2010). The purpose of the study was described to all women, and all information obtained from them was secured and kept confidential (Supplementary material 1). Data were collected from all women who had given their written or oral (for those unable to read and write) informed consent to participate in the study (Supplementary material 2). The names of ethical review committee that approved the study were $\mathrm{Mr}$. MisganawDagnaw, Mr. MullatAgegnihu and $\mathrm{Mr}$. TakeleMessfine (Supplementary material 3as reference number MTYAMSC/11337/2010).

Consent for Publication

"Not applicable".

Availability of Data and Materials

The data sets used and/or analyzed during the current study are available from the corresponding author on reasonable request.

\section{Competing Interests}

The authors declare that they have no competing interests.

\section{Funding}

Authors provided funding for data collection and entry. Any costs for the article covered by the authors.

\section{Author Contribution}

MO: Conceptualization, formal analysis, investigation, methodology, supervision, visualization, writing-original draft, writing-review and editing, and approving the final draft; AM:Conceptualization, formal analysis, investigation, methodology, supervision, editing, and approving the final draft.

\section{Supplementary Matrials}

Supplementary materal1. Confidentiality and informed consent statement

Supplementary materal 2. Consent form

Supplementary materal 3. Ethical clearance

Supplementary materal 4. Englishdata collection checklist

Supplementary materal 5. Amharic version data collection checklist

\section{Acknowledgements}

Authors are grateful to thank the study participants for their valuable contribution. Our appreciation goes to for $\mathrm{Mr}$. DawedGetaw and Mr. MosaSeidu for their proper data collection. We would also like to thank all our friends and families for their encouragement and support during the course of this work.

\section{References}

[1] Leveno K, Cunningham F, Alexander J, Bloom S, Casey B, Dashe J. Williams's Manual of Obstetrics: Pregnancy Complications, McGraw Hill Professional. 2007; 163:63-67.

[2] Niguss Cherie N, Asmerom B. Proportion of Safe Abortion and Associated Factors among Women who Seek Abortion Care Services inFamily Guidance and Marie Stopes International Clinic inDessie Town, North-East Ethiopia. Journal of Public Health andEpidemiology.2017;9(10):27985 .

[3] World Health Organization. Safe and Unsafe Induced Abortion: Global and Regional Levels in 2008, and Trends during 1995-2008, World Health Organization, Geneva, Switzerland, 2012; 2-8.

[4] World Health Organization, Unsafe Abortion Global and Regional Estimates of theIncidence of Unsafe Abortion and Associated Mortality in 2008, World Health Organization, Geneva, Switzerland, 6th edition, 2011.

[5] Induced Abortion Worldwide: Global Incidence and Trends. Fact Sheet, TheGuttmacher Institute, New York, USA, 2018.

[6] Tesfaye G, Teshome M, Semahegn A, Induced Abortion and Associated Factors in Health Facilities ofGuraghe Zone, Southern Ethiopia, Journal of Pregnancy,2014; 1-8.

[7] Gemzell-Danielsson K, KallnerK, Faúndes A. Contraception Following Abortion and the Treatment of Incomplete Abortion, International Journal of Gynecology and Obstetrics, 2014; 126:52-6. 
[8] Induced Abortion and Post Abortion Care in Ethiopia, Fact Sheet, TheGuttmacher Institute, New York, USA, 2017.

[9] Facts on Unintended Pregnancy and Abortion in Ethiopia, IPAS, the Guttmacher Institute. New York, USA, 2017.

[10] Central Statistical Agency, Ethiopia and ORC Macro. Ethiopia Demographic and Health Survey 2011. Addis Ababa, Ethiopia and Calverton, Maryland, USA: Central Statistical Agency and ORC Macro; 2012.

[11] Technical and Procedural Guidelines For Safe Abortion Servicesin Ethiopia, Ministry of Health, Addis Ababa, Ethiopia, 2006.

[12] Singh S, Fetters T, Gebreselassie H. The Estimated Encidence of Induced Abortion in Ethiopia, 2008, InternationalPerspectives on Sexual and Reproductive Health, 2010; 36(1):16-25.

[13] Mpangile S, Leshabari T, Kihwele J. Factors Associated with Induced Abortion in Public Hospitals in Dar Es-Salaam, Tanzania.1992.

[14] Wilson A. Prepared Remarks for the International Planned Parenthood Federation Conference on Unsafe Abortion and Post Abortion Family Planning in Africa, 1994; 102-45.

[15] Justesen A, Kapiga SH, Van Asten AG. Abortions in a Hospital Setting: Hidden Realities in Dar Es-Salaam, Tanzania, Studies in Family Planning, 1992; 23(5):325-29.

[16] Judith W, Elizabeth O, Noel M. Post Abortion Care, a Reference Manual for Improving Quality of Care, Post AbortionCare Consortium, 1995; 9 (16):1-9.

[17] Hassen F, Analysis of Factors for Unwanted Pregnancy among Women in Reproductive Age Group Attending Health Institutions in Jimma Town, 2000.

[18] Post Abortion Care Consortium Community Task Force. Essential Elements of Post Abortion Care: an Expanded and Updated Model, Post Abortion Care Consortium, 2002.

[19] Madebo T, G/Tsadik T. A six-month Prospective Study on Different Aspects of Abortion, Ethiopian Medical Journal,1993; 31(3):165-72.
[20] Senbeto E, Degu G, Abesno N, Yeneneh H. Prevalence and Associated Risk Factors of Induced Abortion inNorth-West Ethiopia, Ethiopian Journal of Health Development,2005; 19 (1):38-44.

[21] Admasie A, Nigussie K, Mekonen T. Magnitude and Risk Factors of Abortion among Regular Female Students in WolaitaSodo University, Ethiopia, Bio Med Central Women's Health, 2014; 14 (50): 2-9.

[22] Awusi VO, Okeleke V. Post Induced Abortion Morbidity and Mortality in Oleh, Nigeria, Benin Journal of Postgraduate Medicine, 2011; 12 (1).

[23] Sibihatu B, Zerezghi H, Asrat K, Tsegai T. Determinants of Immediate Complications of Abortion: A Study Done in Mekane-Hiwot Maternity, Eritrea. Journal of Eritrean Medical Association, 2006.

[24] Worku S, Fantahun M. Unintended Pregnancy and Induced Abortion in a Town withaccessible Family Planning Services: The Case of HararinEastern Ethiopia, Ethiopian Journal of Health Development, 2006; 20 (2): 80-83.

[25] Kebede S, Jira C, W/Mariam D. A Survey of Illegal Abortion in Jimma Hospital Southwest Ethiopia, Ethiopian Medical Journal, 2000; 38(1): 35-42.

[26] W/ Meskel Y, Chekol A. Induced Abortion and Prevalence of Sexually Transmitted Infections and Contraceptive Behavior in Abortion Cases, Gambella Hospital, Ethiopian Journal of Health Development, 1999; 9(2):77-83.

[27] Desalegn M. Abortion as a Social Problem in Jimma Town, South-West Ethiopia, Department of Sociology, Addis Ababa University, 1993.

[28] IvaluBonnen K, Negussie D, Rasch V. Determinants of First and Second Trimester Induced Abortion: Results from a Cross-Sectional Study Taken Place 7 Years After Abortion Law Revisions in Ethiopia, Bio Med Central Pregnancy and Childbirth,2014; 14 (416):3-9.

[29] Yilma M, Fikre E, Ahmed A, Hailemichael G, Lukman Y. Fertility Awareness and Post Abortion Pregnancy Intention in Addis Ababa, Ethiopia, Ethiopian Journal of Health Development, 2003; 17(3): 167-174. 